\title{
Un aparato ortopédico para el magisterio: la Dirección General de Educación Primaria y los maestros en el Distrito Federal, 1896-1913
}

\section{An Orthopedic Device for Teaching: \\ The General Directorate for Primary Education and the Teachers of the Federal District, 1896-1913}

\author{
Ma. Eugenia Chaoul Pereyra \\ Instituto de Investigaciones Dr. José María Luis Mora | mchaoul@institutomora.edu.mx
}

\begin{abstract}
Resumen
Al convertirse en empleados federales en 1896, los maestros de primaria del Distrito Federal y de los territorios (Nayarit y Baja California) ocuparon un papel singular para poner en marcha la política educativa del régimen porfiriano. En el marco de la anhelada centralización educativa, las autoridades promovieron que los docentes se desempeñaran como agentes modernizadores y pudieran difundir los nuevos contenidos pedagógicos. Sin embargo, la estructura burocrática diseñada para tal fin derivó en un aparato que supervisó, controló e inmovilizó a los maestros relegándolos a ocupar un papel receptivo, secundario y dependiente de los favores de la autoridad. Este desempeño fue crucial para entender las características que adquirió la organización magisterial al despuntar la revolución.
\end{abstract}

Palabras clave: magisterio; burocracia; corporativismo; Dirección de Educación Pública.

\begin{abstract}
Once they became federal employees in 1896, the primary teachers of the Federal District and the territories (Nayarit and Baja California) played a special role in setting in motion the educational policy of the Porfirian regime. Within the context of the long-awaited educational centralization, the authorities encouraged teachers to act as agents of modernization and to disseminate the new pedagogical contents. However, the bureaucratic structure designed for this purpose became an apparatus that supervised, controlled and immobilized teachers, relegating them to a receptive, secondary role, dependent on favors from the authorities. This performance was crucial to understanding the characteristics acquired by the teachers' organization at the outbreak of the revolution.
\end{abstract}

Key words: teaching; bureaucracy; corporatism; General Directorate of Public Education.

Fecha de recepción: 2 de septiembre de 2014 Fecha de aceptación: 12 de enero de 2015

Secuencia, ISSN 0186-0348, núm. 95 | mayo-agosto de 2016 | pp. 63-90 


\title{
Un aparato ortopédico para el magisterio: la Dirección General de Educación Primaria y los maestros en el Distrito Federal, 1896-1913
}

\author{
Ma. Eugenia Chaoul Pereyra
}

U

na comitiva con varios profesores de las escuelas municipales de la ciudad de México se dio cita en una solemne reunión con el fin de despedirse de sus antiguos superiores y ponerse a disposición de los nuevos. Los maestros habían sido reconocidos por su larga trayectoria al frente de los planteles y querían dar las gracias al Ayuntamiento por los años que habían estado bajo su tutela. Los nombres de Estanislao Valiente, Andrés Oscoy, Amelia del Toro, entre otros, volvían a estar presentes en las notas de los periódicos. Esta vez se trataba de unas líneas en El Nacional del 3 de julio de 1896 que daba cuenta de cómo los profesores municipales formarían parte del Ministerio de Justicia e Instrucción Pública e invitaban a sus colegas de las escuelas nacionales a trabajar en conjunto. ${ }^{1}$

La noticia tenía relación con un suceso que marcaría la suerte de los maestros, pues el 19 de mayo de ese mismo año el gobierno federal había creado la Dirección General de Instrucción Primaria "a fin de que esta se difunda $\mathrm{y}$ atienda con uniformidad, bajo un mismo plan científico y administrativo". Esta oficina tomó a su cargo la operación técnica y organizativa de todas las escuelas primarias en el Distrito Federal y territorios y a partir de entonces los ayuntamientos cesaron definitivamente la injerencia que por 29 años habían tenido en el manejo de la educación pública. ${ }^{2}$ La Dirección sería una pieza importante en una administración centralizada pues se pensaba que mediante este despacho se lograría la proyección de un sistema educativo uniforme que en un futuro podía ser puesto en marcha para toda la república, lo que redundaría -según se había planeado- en una oficina moderna, con miras al control de la información, al manejo de los programas educativos y a la profesionalización del personal docente.

${ }^{1}$ Los profesores de las escuelas municipales. El Nacional, 3 de julio de 1896, p. 2.

${ }^{2}$ Decreto que reorganiza la instrucción pública y establece la Dirección General de Instrucción Primaria. 19 de mayo de 1896 (en Dublán y Esteva, 1898, t. xxvi, pp. 174-175). 
El cambio de adscripción de los profesores municipales a ser empleados federales representó un giro de la estructura burocrática que había prevalecido a lo largo de casi 30 años. El objetivo de este artículo es entender las características del nuevo ordenamiento y cuáles fueron las consecuencias del cambio para este grupo de empleados a lo largo de los 18 años que funcionó la Dirección. El nuevo rumbo tanto de las reglas como de la organización permitirá entender las condiciones laborales y el papel de los maestros como actores importantes al iniciar el siglo xx.

El propósito de abordar esta problemática desde el funcionamiento institucional es atender un asunto que la historiografía ha dado por sentado. Es cierto que algunos estudios han analizado la situación de los maestros durante esta época y han hecho énfasis en el estado de desprotección laboral, sin embargo pocos se han detenido a analizar la situación de los sueldos, las prestaciones de los docentes y su desempeño en la burocracia federal. A diferencia de la visión panorámica y de larga duración de las investigaciones que se han hecho (Arnaut, 1996; Galván, 1991), la propuesta aquí presentada es la de analizar detenidamente el aparato que incorporó al magisterio y lo moldeó para los fines de la política educativa.

\section{UN ANHELO HECHO REALIDAD}

Si bien la creación de un mando único para el manejo de las escuelas había sido un anhelo desde 1842 (Fowler, 1996), ${ }^{3}$ la asignación directa de una partida presupuestal federal representó la posibilidad de poner en práctica (¿a prueba?) el principio de racionalización burocrática y la especialización de las funciones administrativas conforme a regulaciones claras (Weber, 1977). Se trataba de dar un viraje de un mando discrecional tal como había sido vista la gestión municipal, hacia una operación más regularizada en torno a las decisiones, lo que debía garantizar -en principio-, no sólo la eficiencia del desarrollo escolar, sino la demostración ante los gobiernos estatales de que la educación primaria podía funcionar bajo "criterios científicos" y a través de una conducción central.

${ }^{3}$ La Dirección General de Instrucción Primaria en 1842 fue asignada a la Compañía Lancasteriana y dependía de la filantropía así como de la aportación voluntaria del Ayuntamiento de México.

\section{()(1) $(9$}


El asunto no resultaba sencillo, pues desde el siglo XVIII los ayuntamientos habían regulado el acceso a las plazas de profesor y certificaban quiénes podían ocupar los puestos en las escuelas. Sin embargo, hacia finales de la década de los años sesenta del siglo XIX, el Ayuntamiento de México tuvo un papel protagónico en la enseñanza gratuita de primeras letras y a partir de entonces tomó a su cargo el mayor número de escuelas que existían en la ciudad. En ese sentido, las mejores plazas y las que estaban más bien remuneradas eran las que otorgaba el municipio, de ahí que se formara un tipo de comunidad magisterial semi cerrada, con poca movilidad de personal y una larga espera para los que buscaban aspirar a un empleo de maestro en la capital (Chaoul, 2002).

Bajo la lógica municipal, los valores que regían el lugar de los profesores en la jerarquía burocrática eran la antigüedad, el prestigio y la experiencia. Casi a la manera gremial, los preceptores más reconocidos del ramo controlaban el acceso a los beneficios de las plazas dando cauce a la certificación de los aspirantes mediante exámenes que ellos mismos supervisaban. Hacia la década de los años ochenta se había consolidado una estructura jerarquizada de tipo piramidal en la que los profesores con más años de servicio lograban acceder al puesto de director y con ello gozaban de grandes prerrogativas. Como parte de sus beneficios, no sólo podían habitar de forma gratuita en el mismo edificio donde se encontraba el plantel, sino además tenían algunas prestaciones, un salario decoroso, la perpetuidad en el puesto y uno o dos ayudantes a su cargo. El prestigio del director era obtenido por el respaldo de los vecinos, quienes reconocían su tarea otorgándole el cuidado de los niños. A medida que una escuela tenía más alumnos, el director obtenía más favores tanto de la autoridad como de los padres de familia y se convertía en un elemento importante para la comunidad. ${ }^{4}$

${ }^{4}$ El caso de Carlos María Aranda es muy representativo. Antes de 1867, Aranda había sido empleado en un almacén de comercio en donde llevaba libros de cuentas, facturas y correspondencia, lo que aprovechó en extremo cuando en la república restaurada dirigió una escuela municipal. En su plantel ofreció clases especiales a los niños y aumentó el número de materias colocando a su establecimiento como uno de los más apreciados. Los mismos profesores manifestaban que el primer premio para la mejor escuela municipal lo tenía asegurado la escuela de Aranda pues era "verdaderamente la primera, tanto por sus brillantes resultados que desde su creación ha dado, como porque en ella se enseñan ramos superiores que en ninguna otra", véase Instrucción pública en general. Vol. 2485, exp. 1017. 1875. Archivo Histórico del Gobierno del Distrito Federal (AHGDF), México. Como director, los vecinos lo consideraban "un hombre amigo del pueblo, amante del pobre". El Ayuntamiento trató de compensar su sueldo en 1870 nombrándolo director de una escuela nocturna consiguiendo con ello 25 pesos adicionales al mes y en 1877 le dio el encargo de distribuir los útiles escolares

\section{()(1) $(3$}


Sin embargo, en 1887 el título de profesor municipal perdió valor frente a la creación de la escuela Normal para varones y la "fábrica" de maestros que significó su puesta en marcha. La esperada profesionalización docente representó una cuña para la autonomía de la gestión educativa municipal, pues se esperaba la conversión paulatina de la planta magisterial bajo los nuevos estándares pedagógicos basados en el desarrollo de las capacidades intuitivas de los niños (Meneses, 1983, p. 326). Desde un inicio, sólo las escuelas Normales (la de mujeres se abrió tres años después) podían expedir los títulos de profesores y validar el ejercicio de la enseñanza primaria en las escuelas públicas (Reglamento, 1887, p. 17). ${ }^{5}$

Ante los imperativos de una ciudad en constante crecimiento, la necesidad de abrir cada vez más escuelas y la presión para contratar normalistas con un mejor sueldo, el municipio de México optó por mantener los gastos educativos bajo control y expandir su planta docente reclutando ayudantes y auxiliares que generalmente serían mujeres y que estarían contratadas con un sueldo menor por no contar con ningún título (Chaoul, 2002).

De esta forma, en mayo de 1896, cuando el gobierno se hizo cargo de las escuelas municipales tanto del Distrito Federal como de los planteles de los territorios, un total de 393 profesores pasaron de un día a otro a ser empleados federales (Chaoul, 2002, pp. 99-100); de ellos, 286 pertenecían al municipio de México. ${ }^{6}$ Más de $60 \%$ de los docentes de la ciudad carecía de título profesional, $61 \%$ eran mujeres y sólo 17\% del personal tenía más de diez años de antigüedad. Con el cambio de adscripción, los profesores perdieron la exclusividad que suponía estar bajo la protección del Ayuntamiento de la capital y en algunos casos perdieron igualmente las prerrogativas asociadas a su trayectoria. También es cierto que bajo la nueva estructura de autori-

con un sobresueldo de quince pesos, véase Instrucción pública en general. Vol. 2487, exp. 1267. 1878. AHGDF, México. En 1882, Aranda fue nombrado parte de la comisión dictaminadora en el Congreso Higiénico Pedagógico (Liceaga, 1949, p. 186). La escuela que presidió obtuvo siempre el primer premio, lo que le significó una remuneración al final de año de 100 o 200 pesos más sin contar con los diplomas y medallas, véase Instrucción pública en general. Vol. 2487, exp. 11245. 1877. AHGDF, México.

${ }^{5}$ Véase Art. 45. Desde el día $1^{\circ}$ de enero de 1877 sólo la Escuela Normal de la ciudad de México tendrá autorización para aprobar a los que aspiren a ejercer el profesorado de instrucción primaria en las escuelas públicas del Distrito Federal y Territorios de Tepic y Baja California.

${ }^{6}$ De los profesores de la capital, 42 ocupaban la plaza de directores, 64 eran directoras, 128 se desempeñaban como ayudantes ( 85 señoritas y 43 señores), 32 eran auxiliares ( 27 mujeres y seis hombres), también había diez profesores de dibujo, nueve de inglés, nueve conserjes $\mathrm{y}$ un inspector.

\section{()(1) $\$$}


dad los sueldos fueron homologados, de tal suerte que un director que antes gozaba de cierto prestigio y que podía ganar hasta 900 pesos anuales, ahora percibiría como todos sus colegas un sueldo de 781 pesos. $^{7}$

Si bien algunos preceptores perdieron privilegios bajo las nuevas reglas, las directoras recibieron en cambio un incremento neto de $30 \%$ sobre su sueldo, mientras que la mayoría de los directores de la capital sólo consiguieron un aumento de $.08 \%$. Por primera vez desde 1867 , cuando la educación se convirtió en un proyecto de Estado, la remuneración de los hombres y las mujeres que ocupaban los puestos directivos de las escuelas gratuitas fue unificada. Aun así, el mayor beneficio fue para los 272 docentes que ocupaban los cargos de ayudantes, pues lograron $38 \%$ de aumento anual, aun cuando la mayoría de ellos no tenía título. ${ }^{8}$

La Dirección General concentró los recursos materiales en manos de Luis E. Ruiz y, a su vez, el Ministerio de Justicia e Instrucción Pública incorporó en su presupuesto todos los gastos administrativos. La oficina de Ruiz empezó a funcionar con cierto margen de autonomía, y para su operación requirió solamente de nueve oficinistas, contando entre superiores y subalternos. Sin embargo, la nueva adscripción de los maestros representó un reto no sólo para garantizar la regularidad en el pago de los sueldos sino para llevar un seguimiento estricto de los nuevos programas pedagógicos.

Dada la complejidad de la operación fueron nombrados doce inspectores para el Distrito Federal y tres delegados para los territorios cuyo papel sería vigilar que los establecimientos cumplieran con las materias oficiales, siguieran el tiempo reglamentario y controlaran la asistencia escolar. Los inspectores serían los ojos de la autoridad y debían supervisar de cerca el desempeño de los directores, "exigir que se empleen los métodos y procedimientos aprobados oficialmente" así como corregir los errores de enseñanza, entre otras funciones. ${ }^{9}$ Muchos de los maestros que gozaban de prestigio o antigüedad en la anterior administración capitalina fueron nombrados inspectores con un sueldo mayor. ${ }^{10}$

${ }^{7}$ Instrucción pública en general. Vol. 2512, exp. 3128. 1896. AHgDF, México.

8 Acuerdo de la Secretaría de Justicia. Planta de las escuelas del Distrito Federal y territorios de Tepic y Baja California. 5 de diciembre 1896 (en Dublán y Esteva, 1898, t. xxvi, pp. 516-518).

${ }^{9}$ Decreto que reorganiza la instrucción pública y establece la Dirección General de Instrucción Primaria. 19 de mayo de 1896 (en Dublán y Esteva, 1898, t. xxvi, pp. 174-175).

${ }^{10}$ Por ejemplo, José Pérez Valiente, José R. Vallejo y Rodríguez Arana fueron profesores con más de 20 años de antigüedad al frente de escuelas municipales y en 1897 se convirtieron

\section{()(1) $\$$}




\section{LOS OJOS DE LA AUTORIDAD}

Como empleados clave al frente de la nueva cadena de mando, los inspectores fueron el puente entre los directores de los planteles y la Dirección General. Esta mediación representó un cambio radical, pues previamente los directores habían tenido una comunicación directa con la autoridad. Esta especie de degradación en la jerarquía burocrática que supuso la interposición de los inspectores no consistió, sin embargo, en una pérdida absoluta de control, ya que el puesto de director les aseguró, como en años anteriores, la posibilidad de habitar en los mismos edificios escolares sin pagar renta y el apoyo de los ayudantes y los auxiliares que trabajaban bajo sus órdenes.

No obstante, esta jerarquía de tipo vertical no era la única, también existía otra, la de carácter "espacial", contemplada a través de aquellos puestos de directores ubicados en las escuelas de las municipalidades más alejadas de la ciudad como Xochimilco, Tlalpan y Cuajimalpa. Ahí las condiciones de los planteles eran poco propicias para que pudieran ejercer su oficio. Los maestros que eran destinados a esas escuelas ganaban un sueldo menor y carecían por completo de beneficios asociados a su cargo, "donde no hay casas que puedan habitar y tampoco hay manera de proveerse de alimentos" ${ }^{11}$ Los maestros que eran comisionados a esos establecimientos llamados foráneos, lejos de los vecinos que habían conocido su desempeño y de la comunidad en la cual habían trabajado toda su vida, decían que "jamás se atiende a sus aptitudes, méritos y tiempo de servicio sino sólo al capricho del autócrata Ruiz". ${ }^{12}$

En efecto, para muchos docentes, el papel de la Dirección no fue acogido con beneplácito. A tres años de su funcionamiento, se acusó a Ruiz de un "manejo despótico". ${ }^{13}$ Para que los profesores lograran una audiencia con el director, desde el punto de vista de los agraviados, era necesario perder mucho tiempo y sufrir muchos desprecios. Los profesores "eran tratados con injustificada dureza y a veces multados sin razón seria y aun despojados de

en inspectores. Como profesores aparecen en Instrucción pública en general. Vol. 2494, exp. 1831. 1885. Como inspectores en "Circulares" (1906).

${ }^{11}$ Los profesores en los Distritos de Xochimilco y Tlalpan. El Popular, 30 de julio de 1897, p. 1.

${ }^{12}$ Respeto al profesorado de Instrucción Pública. Desorden en la Dirección del Ramo. El Popular, 15 de marzo de 1900, p. 1.

${ }^{13}$ Respeto al profesorado de Instrucción Pública. Desorden en la Dirección del Ramo. El Popular, 15 de marzo de 1900, p. 1.

\section{(ㅇ)(1) $(3$}


sus empleos". ${ }^{14}$ Los inspectores, llamados "pequeños sultanes", ${ }^{15}$ acaparaban gran poder y se extralimitaban en sus facultades. A los maestros se les pedían cuotas para todo, "para pagar la fiesta de Hidalgo, contribuciones para paseos y para la celebración del cumpleaños del Director dejándolos con un sueldo miserable". ${ }^{16}$

La inconformidad de los maestros daba cuenta de un tipo de autoridad burocrática cuya legitimidad descansaba en el poder de mando que le otorgaba a Ruiz el puesto. Si bien la intención había sido crear una dirección especializada y profesionalizada, tanto en los aspectos administrativos como en los nuevos conocimientos pedagógicos, que impulsara a los profesores a seguir los lineamientos de los programas educativos de manera voluntaria, la autoridad ejercida, por el contrario, estaba orientada hacia la disciplina y la supervisión, obligando a los subordinados a cumplir con los requerimientos bajo amenaza de sanciones. Esta orientación de tipo coactivo generó una forma específica de acercarse al trabajo docente en la cual los maestros se colocaron como empleados receptivos y dependientes de la autoridad, sin ninguna capacidad de participación ni de generación de propuestas (Blau, 1968).

La conexión entre este tipo de estructura burocrática diseñada con base en la vigilancia del trabajo magisterial derivó en lo que los maestros tradujeron como una pérdida de autonomía dentro del salón de clases. ${ }^{17}$ Los profesores se debían amoldar a las decisiones de la autoridad con respecto al contenido de su trabajo y reportar cada una de sus acciones frente al grupo, llenar innumerables inventarios de libros y muebles y completar formatos semanales sobre la asistencia de sus alumnos. ${ }^{18}$ Los inspectores a su vez in-

${ }^{14}$ El Purgatorio de los profesores, ¿Inspectores o sultanes? El Popular, 18 de febrero de 1900, p. 1.

${ }_{15}$ El Purgatorio de los profesores, ¿Inspectores o sultanes? El Popular, 18 de febrero de 1900 , p. 1. 1897, p. 3.

${ }^{16}$ Ley ¡fuego! contra los profesores de instrucción pública. El Popular, 24 de mayo de

${ }^{17}$ Cuando las escuelas pertenecían al Ayuntamiento, los maestros llegaron a tener algunas iniciativas. Por ejemplo, Carlos M. Aranda propuso una obra elemental sobre dibujo lineal para que fuera admitida como texto en las escuelas municipales: Instrucción pública en general. Vol. 2488, exp. 904. 1871. AHGDF, México. Otro ejemplo es el de Trinidad González Valle, quien también puso a disposición su libro de Ortografía y Gramática: Instrucción pública en general. Vol. 2485, exp. 1064. 1873. AHgDF, México.

${ }_{18}$ En el formato para reportar los inventarios de cada escuela se puede leer: Los directores y directoras de las escuelas presentarán sus listas de pedidos o darán aviso de que no necesitan útiles el día señalado por sus respectivos inspectores administrativos. Por ningún motivo dejarán de manifestar la existencia que tienen en su escuela, de los libros oútiles que solicitan en su pedido. Por cualesquiera

\section{()(1) $\$$}


formaban sobre la habilidad del maestro para controlar el comportamiento de los niños, el arreglo del salón de clases y cómo se cubrían las materias del plan de estudios.

Los profesores se quejaron de que las obligaciones eran tantas que "no les queda ni una hora libre al día y apenas disponen de la noche para dormir". Para muchos docentes la culpa de las fuertes exigencias era de la Dirección, "quien faculta y tolera que los inspectores se extralimiten de sus facultades". Desde el punto de vista de los profesores la instrucción pública podía "ser servida sin tiranía de presidio y para disciplinar al profesorado no es necesario vejarlo ni humillarlo". ${ }^{19}$

\section{EL APARATO ORTOPÉDICO}

Aun así, la ampliación extensiva y cuantitativa de las funciones de la Dirección pronto rebasó a la organización burocrática inicial. La planta docente del Distrito Federal para 1904 estaba conformada por 1619 profesores (548 varones y 1071 señoritas). Gran parte de los profesores había llegado de otros estados y 737 de ellos tenían aún títulos emitidos por los ayuntamientos, 295 eran normalistas de la capital y 442 de otras entidades. $54 \%$ de los maestros, es decir 882, no tenía ningún título (“Informe anual”, 1904). A ocho años de funcionamiento de la Dirección, a 17 años de creada la Normal de la ciudad y después de cuatro generaciones de egresados, la anhelada profesionalización de los docentes no se había logrado.

Es cierto que países como Alemania también se encontraban en un proceso similar, en el que los profesores de las escuelas comunales tenían por ley ser titulados, y para ello el gobierno sostenía en cada ciudad un seminario para su actualización (Lamberti, 1989). Los maestros interinos sin título debían sustentar dos exámenes (uno teórico y uno práctico) a fin de dar prueba

omisión a estas disposiciones se impondrá la pena correspondiente. En otro comunicado se puede leer: "Por disposición del C. Director General de Instrucción Primaria y en cumplimiento de la fracción viII del artículo 68 de la ley reglamentaria de Instrucción, se servirá ud. remitir a esta oficina los datos estadísticos correspondientes al año próximo pasado, llenando los esqueletos que para ese objeto le remito. Siendo urgente el reunir a la mayor brevedad posible los mencionados datos. Dispone el mismo director se imponga una multa equivalente a un día de sueldo al director o directora que para el día primero del próximo julio no los hubiere remitido". Véase Escuela 47, 126 y 89. Vol. 2544, s/exp. 1904. AHGDF, México.

${ }^{19}$ El Purgatorio de los profesores, ¿Inspectores o sultanes? El Popular, 18 de febrero de 1900 , p. 1.

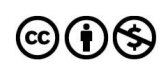


de sus aptitudes, y aquellos que no fueran competentes no podían acceder al puesto. Además, el gobierno alemán proporcionaba habitación tanto a los directores como a los maestros y un sueldo proporcional en razón de los años de servicio. ${ }^{20}$

En el caso de México, la profesionalización y la estructura burocrática tomaron otro rumbo. Los maestros tenían un sueldo fijo en razón de su puesto, no de su experiencia, y sólo eran acreedores a una medalla y a un diploma por los años de servicio. Se estipuló también que para obtener la jubilación con goce de sueldo era necesario contar con 30 años de servicio. Más que alentar la carrera magisterial, el Ministerio de Justicia e Instrucción Pública tenía puesta la mira en planear a futuro la política educativa y definir los contenidos y el rumbo a seguir a fin de lograr la uniformidad en todo el país.

Al dejar Ruiz el puesto de la Dirección en 1904, Manuel F. Martínez tomó el timón. A diferencia de su predecesor que se decía un teórico de la pedagogía, Martínez era un "organizador y un profesor", su trayectoria lo había traído a la capital desde Monterrey, en donde había sido maestro e inspector. Ingeniero de profesión, en su tierra natal había fundado una Normal para maestros y se distinguió como experto educador en el Congreso Pedagógico de 1889 (Meneses, 1983, pp. 609-610). Como hombre práctico, una de sus primeras acciones fue atraer a los docentes y revivir la Academia de profesores dándole un carácter obligatorio a las sesiones que se celebrarían el cuarto sábado de cada mes ("Acuerdo", 1904).

La Academia tenía sus antecedentes en una agrupación fundada en 1882 que había sido auspiciada por el Ayuntamiento como un espacio de sociabilidad para los profesores municipales de la capital. Los docentes que pertenecían a la Academia podían dictaminar libros de texto y opinaban acerca de las experiencias de sus colegas. ${ }^{21}$ Sin embargo, al paso del tiempo esta agrupación no prosperó, y se desprendieron de ella varias sociedades independientes fundadas por los propios maestros, como la de José R. Vallejo y la de Andrés Oscoy. Tiempo después apareció otra más a cargo de Ramón Manterola y Carlos A. Carrillo. Finalmente en 1894, el regidor de Instrucción Pública del Ayuntamiento logró reunir todas estas sociedades bajo una sola reconocida como Academia de profesores municipales (segun-

${ }^{20}$ La experiencia alemana se puede apreciar también en el Boletín de Instrucción Pública, $v(8), 10$ de abril de 1906, lo cual indica que era un referente en la época.

${ }^{21}$ Algunas obras fueron remitidas a la Academia para que esta organización emitiera su opinión sobre "las pretensiones de los autores", véase Instrucción pública en general. Vol. 2491, exp. 1536. 1882. AHGDF, México.

\section{()(1) $(3$}


da vida por decirlo de alguna manera). Al ser presidida por el gobernador del Distrito Federal tuvo un mayor impacto, pues no sólo su objetivo era brindar lugares para el estudio y actualización del magisterio sino también organizar la ayuda mutua y la caja de ahorros entre los socios que ejercían la docencia ("La Academia", 1904). ${ }^{22}$

Al federalizarse la educación la Academia perdió vigencia, pero Martínez tenía otros planes. Antes de reorganizarla, se aseguró de convertirla en una institución dedicada a los estudios pedagógicos dependiente de la Dirección General y separó de ella la función de ayuda mutua y la caja de ahorros. Los socios activos eran los inspectores y los directores de la capital, quienes debían presentar a sus colegas los programas aprobados por el Consejo de Educación; los socios corresponsales eran los directores de las escuelas en las municipalidades y de las escuelas mixtas. Los ayudantes y profesores de las materias especiales debían asistir a las sesiones en calidad de oyentes ("Bases constitutivas", 1904).

La gran mayoría de los maestros fueron concebidos como alumnos que debían aprender para enseñar y pasar lista de asistencia. Su única función era escuchar las cátedras sobre cómo se debía dar una clase con los temas pedagógicos más novedosos. Con la Academia y la calidad de los socios quedó también refrendada una estructura de tipo corporativo donde los inspectores y después los directores de la capital eran los encargados de escenificar las clases que debían reproducir los maestros en sus respectivos grupos. Los inspectores demostraban su lealtad a la Dirección al asegurar un quórum importante para las sesiones con los empleados de su zona. A cambio, podían ser premiados con prestaciones y becas. Lo mismo pasaba con los directores, quienes al tener control sobre sus ayudantes conservaban los beneficios asociados a su puesto.

Quien definía "desde arriba y desde fuera" los contenidos educativos era el Consejo Superior de Educación, creado en 1901 como un cuerpo colegiado inserto entre la Dirección General y la Subsecretaría se Instrucción Pública (Cano, 2000, p. 220; Meneses, 1983, p. 506). El Consejo tenía carácter consultivo y se encargaba de las cuestiones técnicas. Tanto la planeación de la enseñanza como las decisiones recaían en un grupo de "notables" que defi-

22 Todavía en 1900 la sociedad de profesores independientes anunciaba su convocatoria para que todos los socios participaran en la junta electoral. Véase Sociedad de profesores. El Popular, 9 de marzo de 1900, p. 2.

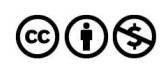


nían las actividades, métodos y contenidos, mientras los profesores eran los engranajes de una gran burocracia educativa. ${ }^{23}$

Al tiempo que el Consejo disponía las materias y las adecuaciones pedagógicas, las funciones administrativas y de vigilancia del magisterio le correspondían a la Dirección. Para 1904 la organización de la educación primaria adquirió una mayor relevancia no sólo por el presupuesto asignado y el crecimiento en el número de maestros, sino porque Martínez, hombre cercano a Justo Sierra cuando fue subsecretario de Instrucción Pública en 1901, sería el encargado de allanar la difícil tarea de administrar y poner orden en la educación elemental y superior así como preparar el camino para que, en 1905, Sierra mismo fuera nombrado ministro de la flamante Secretaría de Instrucción Pública y Bellas Artes.

\section{EL INFRANQUEABLE CAMINO DEL ESCALAFÓN}

Para atender las necesidades del sistema educativo, específicamente la operación en lo que respecta a la concentración de información y la vigilancia del desempeño de los docentes, en 1905 la Dirección se convirtió en una organización mayor con seis secciones, un jefe al frente de cada una de ellas y varios escribientes, lo que ascendía a 52 el número de empleados. ${ }^{24}$ La inspección a

${ }^{23}$ Algunos de estos notables asesores que formaron parte del Consejo fueron los abogados Miguel y Pablo Macedo, Manuel M. de Zamacona, Joaquín Casasús, Ezequiel A. Chávez, Rosendo Pineda y Jorge Vera Estañol (quien sería secretario de Instrucción Pública después de la dimisión de Díaz), médicos como Eduardo Liceaga, Luis E. Ruiz (quien permaneció en el Consejo después de dejar la Dirección de Educación Primaria) y Francisco Vázquez Gómez (quien sería secretario de Instrucción Pública durante el interinato de De la Barra). También fueron consejeros los educadores Enrique Rébsamen, Gregorio Torres Quintero, Alberto Correa y Leopoldo Kiel (estos últimos fueron directores de la Escuela Normal de Maestros), Daniel Delgadillo y Adrián Fournier (dueño del prestigiado colegio privado Fournier), Rafaela Suárez (directora de la escuela Normal de Maestras), Raquel Santoyo (directora de la escuela primaria anexa a la Normal) y maestras destacadas como María Llamas Bello y Cecilia Mallet (directora del Colegio La Paz).

${ }^{24}$ Para 1904 la sección primera tenía a su cargo todo lo relativo a las escuelas particulares del Distrito Federal además de los asuntos correspondientes a conferencias, fiestas escolares, oposiciones, exámenes de admisión, textos y excursiones escolares. La sección segunda se encargaba de todas las escuelas públicas del Distrito Federal. La tercera, de las escuelas de los territorios; la cuarta, de la estadística escolar y la vigilancia de la instrucción obligatoria; la quinta era la que llevaba los asuntos de contabilidad, compra de libros y muebles, y la sexta era la proveeduría general encargada de repartir los libros, enseres y útiles para las escuelas. Véase "Informe anual", 1904.

\section{()(1) $\$$}


su vez estaba dividida en varias secciones: la pedagógica, la administrativa, la médica y la arquitectónica. Los inspectores pedagógicos eran siete y estaban encargados de recorrer las escuelas y celebrar semanalmente las conferencias a las cuales los maestros estaban obligados a asistir.

Los cinco inspectores administrativos se encargaban de la parte material y disciplinaria de los establecimientos, y los tres inspectores médicos de visitar a los profesores enfermos, emitir certificados para otorgar licencias con goce de sueldo y revisar la higiene de los planteles. Al convertirse la instrucción pública en una secretaría de Estado, los maestros, por decreto presidencial, fueron homologados como cualquier empleado federal para el auxilio de gastos de inhumación ("Circular relativa al auxilio", 1906).

Sin embargo, la composición salarial de los docentes mantenía un escalafón infranqueable. Mientras el sueldo de los inspectores era de 23440 pesos anuales, el de los directores era de 803 pesos netos más el beneficio de la renta de la casa habitación donde vivían y se encontraba la escuela. Los ayudantes ganaban 602 pesos anuales y los profesores de materias especiales como canto y dibujo 482 pesos. Sólo el costo de operación de la oficina de la Dirección en 1906, por ejemplo, fue de 158771.10 pesos, lo que equivalía a $2.70 \%$ del presupuesto de la Secretaría; en tanto que mantener la puesta en marcha de las escuelas en ese mismo año ascendió a una tercera parte (29\%) del presupuesto del ramo. El cambio de tamaño del gobierno docente había sido exponencial y las consecuencias para los maestros también ("Presupuesto", 1908).

Así como estaba estructurada la Academia de profesores, la posibilidad de ascenso de los docentes hacia los puestos más altos era poco frecuente. En cambio, la rotación y contratación de personal se llevaba a cabo de forma horizontal hacia la base, en las plazas de ayudantes. En 1906, por ejemplo, se debió aumentar el presupuesto para cubrir los requerimientos de estos puestos, en los que tendrían prioridad para su reclutamiento aquellos maestros titulados de las escuelas normales de la capital, en segundo lugar los titulados de las normales de los estados y, por último, "los profesores antiguos que hayan prestado buenos servicios en las escuelas foráneas" ("Adiciones y reformas", 1906).

El escalafón se expresó también de forma "espacial", pues conforme los maestros se hicieran acreedores a un buen historial debían ser atraídos progresivamente hacia los lugares más próximos a la capital. Para las escuelas foráneas eran preferidos aquellos docentes con títulos del Ayuntamiento y los que "no estén prestando servicios suficientemente satisfactorios en la capital", es decir, los que no eran considerados buenos maestros eran enviados

\section{()(1) $(3$}


lejos a encargarse de escuelas de segunda clase a manera de castigo (véase gráfica 1) ("Dictamen de la Comisión", 1908).

Otro rasgo de la contratación de los ayudantes es que, debido a lo exiguo del sueldo, el puesto de maestro se convirtió en un trabajo casi exclusivo del profesorado femenino y existía muy poca oferta de varones para ocupar esos cargos (véase gráfica 2) ${ }^{25}$ La gran mayoría de las señoritas que cubrían las vacantes, aún en las escuelas de niños, carecía de algún título, y los inspectores las capacitaban en tres meses para presentar un examen de admisión que les permitiera ejercer. Llamadas señoritas "de admisión" ("Una iniciativa", 1909) tenían un sueldo casi igual al de las normalistas, lo que provocaba un conflicto de intereses al interior de la planta de empleados (véase gráfica 3).

Los ayudantes eran considerados los soldados del magisterio porque estaban "frente a frente del niño" ("Discurso", 1906). Eran los encargados del grupo y los que recibían las órdenes del director del plantel. Se les exhortaba a ser el primer ejemplo para los alumnos, el que debía presentarse con puntualidad, tener un trato afectuoso e imparcial, carácter amable, tener la exactitud por el trabajo, "recta justicia y energía en sus actos, bondadoso, indulgente con todos" y paciencia suficiente para reprender a sus alumnos ("Deberes oficiales", 1911). El ayudante tenía la obligación de hacer la provisión de muebles y útiles para su salón de clases y asistir a las reuniones mensuales obligatorias de la Academia de profesores, así como a las conferencias pedagógicas de ramos especiales que tenían lugar una o dos veces por semana ("Circulares", 1904a). Se les instaba a que fueran "los artífices de la obra santa y lograr con [su] ejemplo que nadie piense en sí mismo sino en cuanto sea necesario para poder pensar mejor en los demás y hacer a los demás felices" ("Discurso", 1906).

Por su parte, el director de la escuela podía designar el grupo que le correspondía a cada ayudante. Estaba facultado para hacer modificaciones a la distribución del tiempo con el solo requisito de consultar la aprobación del

${ }^{25}$ Esto no quiere decir que la feminización del magisterio mexicano se haya debido sólo al sueldo. Como bien lo demuestra Cortada (2000, pp. 35-56) para el caso de España, las maestras se afianzaron a sus lugares de trabajo en las escuelas de párvulos y en las de niñas y ejercieron para el caso de ese país una presión importante para igualar su remuneración con la de los varones. También Cano (2000, pp. 206-243), para el caso de México, muestra cómo la contratación de mujeres obedeció a un fenómeno cultural y de género. Sin embargo, para futuras investigaciones será necesario tomar en cuenta las facilidades para la contratación femenina y la movilidad laboral de las mujeres como circunstancias que favorecieron también la feminización del magisterio en el caso de México.

\section{()(1) $\$$}




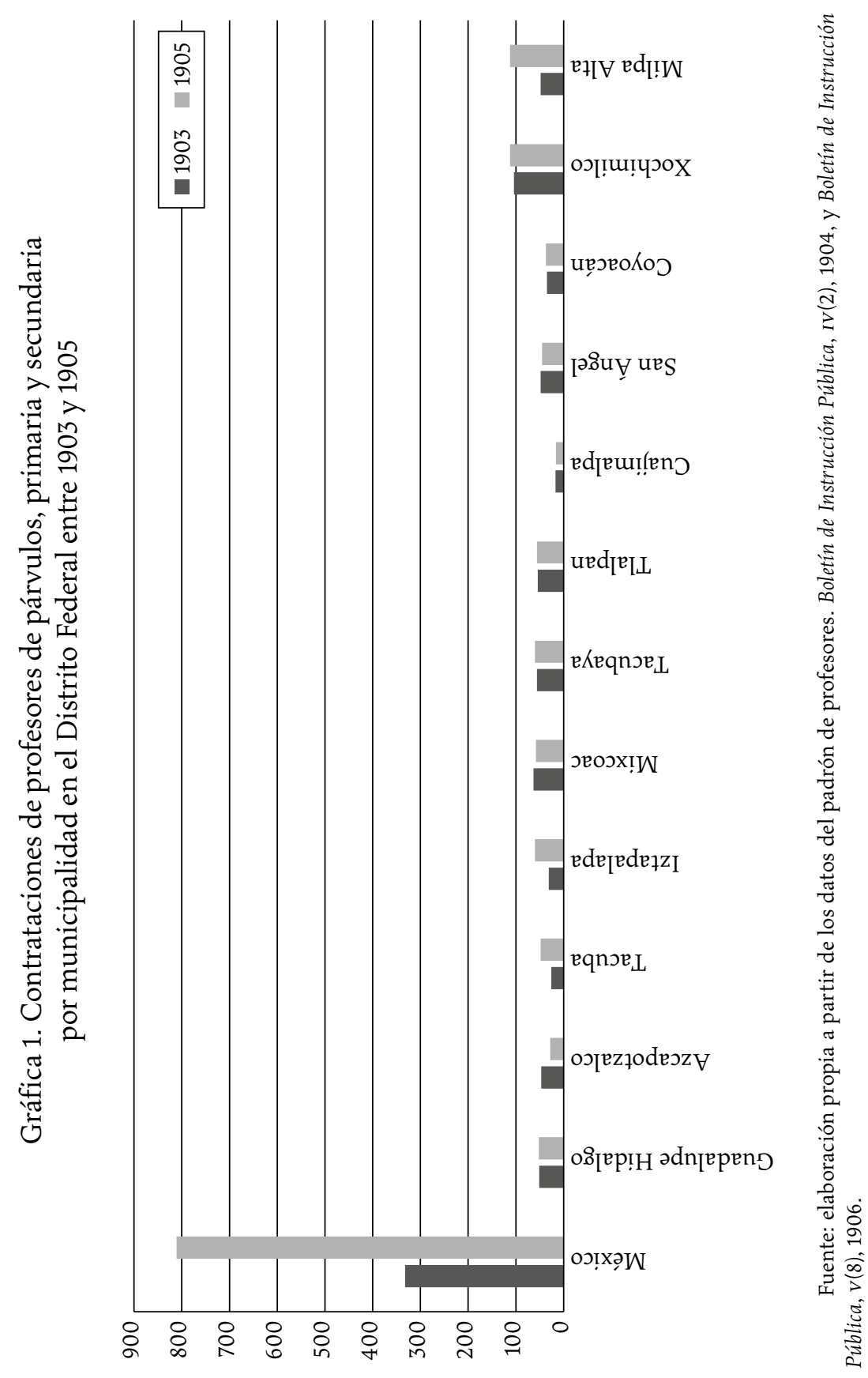

\section{(ㄷ)(1)(8)}


Gráfica 2. Contrataciones de profesores de primaria por puesto y género en el Distrito Federal entre 1903 y 1905

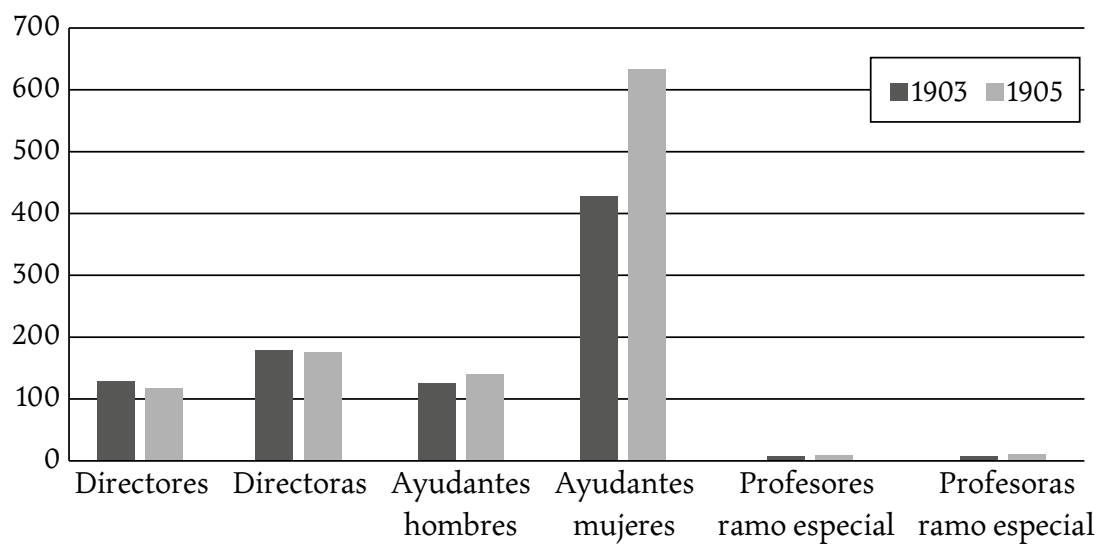

Fuente: elaboración propia a partir de los datos del padrón de profesores. Boletín de Instrucción Pública, IV(2), 1904, y Boletín de Instrucción Pública, v(8), 1906.

Gráfica 3. Número de profesores y profesoras de primaria y secundaria contratados entre 1903 y 1905 en el Distrito Federal

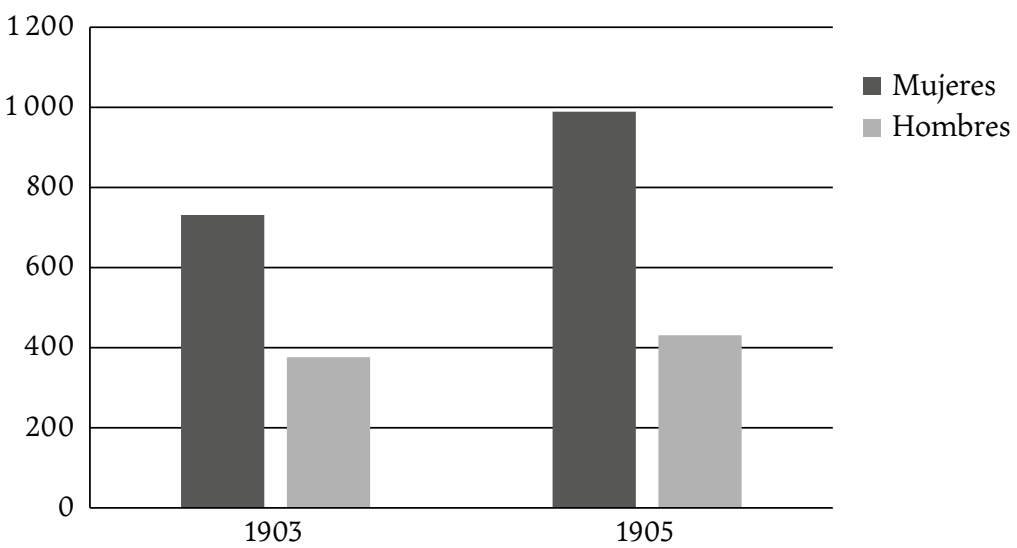

Fuente: elaboración propia a partir de los datos del padrón de profesores. Boletín de Instrucción Pública, IV(2), 1904, y Boletín de Instrucción Pública, v(8), 1906.

\section{(ㄷ)(1) $\$$}


inspector administrativo. Podía exigir a los ayudantes toda clase de trabajos que se relacionaran con el establecimiento aun cuando tuvieran que hacerse en horas extraordinarias. El director, en suma, era el encargado de dictar "las disposiciones conducentes para guardar el orden y compostura en todos los movimientos de los alumnos" y mantener relaciones amistosas con las familias. Según el inspector Bonilla, su autoridad no debía reducirse a la escuela sino extenderse hasta la calle y aun hasta el hogar. ${ }^{26}$

Los directores fungieron como el canal oficial para que los ayudantes y los profesores especiales pudieran tratar los asuntos relacionados con las licencias con o sin goce de sueldo y para cualquier asunto laboral, lo que los colocó en una posición de poder importante frente a sus subordinados ("Circulares", 1904a).

Para la Dirección General, la jerarquía interna de cada plantel debía demostrarse en los saludos semanales a la bandera: "queremos que el director [...] encabe[ce] el desfile, siendo el primero en rendir su homenaje patrio, que en seguida cada uno de los profesores ayudantes guiando a sus respectivos grupos hicieran propia la reverencia" ("Los profesores", 1909). En ocasiones, los directores eran los dueños del lugar donde se ubicaba el plantel, y fueron advertidos constantemente de no hacer modificaciones materiales a la escuela en función de sus necesidades privadas o familiares ("Circulares", 1904b). Se les solicitó que cuando se celebrara su cumpleaños no suspendieran las clases del establecimiento "con el fin de que profesores y alumnos tomen parte de ellas, ni porque hayan de adornarse los salones correspondientes" ("Circulares", 1904b). La Dirección General envió varias disposiciones para que no se sirvieran de los niños como "criados domésticos de servicio personal". Si bien se comentaba en la prensa que con frecuencia los alumnos eran

${ }^{26}$ En un comunicado del 5 de diciembre de 1900 al director de la escuela 47 se lee: "Por acuerdo del C. Director General digo a ud. que los informes que envíe a esta oficina han de ser tomados directamente y no de las noticias que le rindan los señores empadronadores. Por consiguiente y a fin de que el trabajo de empadronamiento se haga lo mejor posible, debe ud. recorrer manzana por manzana y casa por casa anotando cuidadosamente las deficiencias que observe para comunicarlas a esta oficina la cual dictará las medidas que sean necesarias para corregirlas”. Escuela elemental 47, 126 y 89, vol. 2544, s/exp. 1900. AHGDF, México. En un artículo escrito en La Enseñanza Primaria, el inspector Bonilla (1908) aclara "es muy frecuente ver que tan pronto como los alumnos salen hasta la calle y aún hasta las puertas mismas del establecimiento forman corrillos en los que salen desde luego a lucir los cigarrillos y se escuchan risotadas poco pulcras. Un buen director no debe hacerse de la vista gorda, no debe permitir faltas de respeto a su persona o a los profesores."

\section{()(1) $\$$}


mandados a comprar cigarros, llevar recados, traer prendas de ropa, a barrer y a limpiar la escuela. ${ }^{27}$

Los inspectores, como supervisores de cada zona escolar, tenían la obligación de visitar las escuelas de su jurisdicción y proponer el personal adecuado. Entre sus funciones tenían el derecho de otorgar a los directores licencias y debían procurar "que impere la mayor conformidad y armonía entre los empleados". Promovían los ascensos y recompensas a favor de los maestros así como también aplicaban las penas disciplinarias y las amonestaciones. Para acceder al cargo debían haber desempeñado previamente con acierto los puestos de director de escuela elemental y superior ("Proyecto de reglamento”, 1911). Era un requisito no normado pero sí esperado que todos los integrantes de la planta docente federal fueran sanos y no presentar deformidades que los hicieran repulsivos o "que los convirtieran en objeto de mofa de los educandos" ${ }^{28}$

En términos generales, muy pocos podían acceder al puesto de inspector o de director, y como los ayudantes estaban mal remunerados, había poca permanencia. La constante demanda para cubrir de ayudantes las escuelas y la incapacidad de las Normales para abastecer con maestros a los planteles hacían que el título de normalista fuera prescindible. Esto trajo otra implicación mayor. Si el personal contratado tenía tan poca calificación debía esperarse la guía y supervisión cercana. ¿Por qué entonces sólo había siete inspectores pedagógicos y cinco administrativos para supervisar más de mil profesores entre ayudantes y directores? Mi argumento es que se trataba de una estructura centralizada de autoridad basada en un sistema de premios, castigos y cuotas para la compra de favores, que facilitaba el mando de un solo lado y poca retroalimentación de los subordinados hacia la Dirección.

El sistema de premios y castigos se presentaba a partir de criterios tales como el "empleado modelo", y se consideraban en ese rango aquellos docentes que mejoraban "los detalles en la ejecución y tenían un gran sentimiento de responsabilidad" ("Deberes", 1909). Los empleados modelo eran reconocidos con felicitaciones públicas en las revistas especializadas, ${ }^{29}$ en tanto que los inspectores normalistas "modelo" eran premiados con becas o comisio-

${ }^{27}$ El servicio de los niños como criados de las escuelas. El Educador Moderno, 31 de enero de 1910 , p. 1.

${ }^{28}$ Causas que impedían ejercer el oficio de maestro eran por ejemplo, la tuberculosis, el mal de Lázaro, las cataratas, el asma, las varices que dificultaban la marcha, las deformaciones, la artritis, entre otras ("Circulares", 1911).

${ }^{29}$ Véanse las menciones en todos los tomos de La Enseñanza Primaria.

\section{()ㅜ(1) $\$$}


nes para ir a Europa o a Estados Unidos. ${ }^{30}$ También eran exhibidos aquellos maestros, generalmente ayudantes, que eran suspendidos por abandono de empleo ("Circulares", 1904c); los que cometían una falta de subordinación, ${ }^{31}$ o bien de puntualidad y desempeño. ${ }^{32}$ Los directores que se negaran a dar las clases prácticas en las conferencias sabatinas en la Academia eran advertidos de cometer una indisciplina que iría a su hoja de servicios ("Circulares", 1905). El control directo (centralizado) de mando dependía más de los juicios personales del jefe inmediato superior que de un control normativo impersonal. Esta dinámica impidió que los profesores pudieran realizar una carrera dentro del orden jerárquico, y los cargos se veían como privilegios para los mismos empleados de siempre.

\section{LOS PROFESORES Y LOS FINES DE LA POLÍTICA}

El 15 de agosto de 1908 la Secretaría de Instrucción Pública y Bellas Artes emitió la ley de educación primaria que representaba la síntesis de la reforma educativa. Con la nueva legislación, la educación elemental había conservado su carácter obligatorio, gratuito y laico pero había agregado otros dos requisitos más. Tendría que ser integral y nacional. Como parte del proyecto político educativo del porfiriato por fin se veía cercano el tan anhelado principio de uniformidad de contenidos para todo el país y el control del Estado. Esta ley, confeccionada desde el Consejo Superior de Educación como cuerpo consultivo cercano a la Secretaría, también había previsto -aun sin injerencia alguna de los profesores activos- la importancia de los sueldos y prestaciones, y por primera vez se fijó un escalafón en función de los años de antigüedad y de la titulación de los maestros ("Proyecto de ley", 1908).

En efecto, Sierra sabía que sin la planta docente sería imposible llevar a la práctica la nueva legislación. Es por ello que en diciembre de 1908 lanzó la iniciativa a los profesores para crear una Asociación Nacional del Magisterio

${ }^{30}$ Pongo un ejemplo entre varios, el normalista Toribio Velasco, inspector de zona, "quien fue comisionado por la superioridad para ir a Europa a estudiar inspección escolar" (“Deberes", 1909).

${ }^{31}$ Instrucción pública. Dirección General. Vol. 2548, exp. 6. 1907. AHGDF, México. "El C. Director General en uso de la facultad que le concede la fracción vini del artículo 67 de la ley reglamentaria de instrucción obligatoria ha tenido a bien suspender a usted en el ejercicio de sus funciones como ayudante de esa escuela por el término de ocho días por falta de subordinación al C. Inspector Estanislao Pérez Valiente. 2 de junio de 1902".

${ }^{32}$ Instrucción pública. Dirección General. Vol. 2548, exp. 6. 1907. AHGDF, México.

\section{()(1) $\$$}


que tuviera como fin establecer el mutualismo, el estudio de cuestiones educativas y la utilización de la prensa y congresos para la investigación pedagógica. Sería condición, sin embargo, que la Asociación se mantuviera neutral de todo asunto político y religioso y que "jamás en su calidad de Cuerpo hará gestiones encaminadas a pedir el cambio de legislación vigente" ("La Asociación”, 1909).

Se trataba de una organización creada desde arriba que aseguraba la lealtad de los maestros para organizar y conseguir la federalización educativa. Una asociación dependiente de la Secretaría que ofrecía como beneficio para los docentes el cuidado de la aportación de cada asociado para que las familias recibieran "una cierta cantidad de dinero muy superior a la suma de sus cuotas" a cambio de su apoyo incondicional. No obstante, para que la sociedad fuera verdaderamente significativa, se proponía que el mutualismo debía ser nacional y no regional ("La Asociación”, 1909).

La Asociación Nacional del Magisterio estaría integrada por juntas locales provisionales formadas por profesores titulados de las normales y maestros "de la falange de educadores, que aunque no sean normalistas han obtenido un puesto prominente por sus méritos" ("Iniciativa para la organización”, 1909). Estas juntas se reunirían para tratar de unificar reglamentos y posteriormente se disolverían en una confederación en la que estarían representados los profesores de todo el país. ("Informe de los trabajos", 1911). Para abril de 1910 se establecieron en la capital cinco juntas locales y ocho en las municipalidades, todas ellas presididas por los jefes de sección de la Dirección General que, como alfiles del secretario, tenían la encomienda de agrupar el mayor número de docentes. A ellas se les sumaron una junta de Chilpancingo y otra de Zacatecas, también encomendadas a empleados de la propia Dirección. En casi todas las juntas locales estaban inscritos maestros de las escuelas públicas así como de escuelas particulares y profesores retirados. Por lo general las juntas de la capital estaban constituidas por señoritas, mientras que las demás eran de ambos sexos ("Informe de los trabajos", 1911).

Pese a los esfuerzos por unificar criterios, un año después muchos maestros no habían aceptado aún la invitación para integrarse en una junta local por la "duda acerca de la mucha o ninguna connivencia que esta puede tener con la administración pública escolar" ("Informe de los trabajos", 1911). La distancia entre los maestros y las autoridad era palpable, y la fragmentación al interior del magisterio también. Sin embargo, para entonces la presión de los grupos armados en el norte del país había influido para que a finales de marzo de ese mismo año el presidente Díaz exigiera la dimisión de

\section{(ㅇ)(1) $(9$}


su gabinete completo. Justo Sierra, como los otros ministros, fue depuesto del cargo, y Jorge Vera Estañol, un abogado "sin color político" (Vera, 1957, p. 78), quedó al frente de la Secretaría de Instrucción Pública para ayudar a bien morir a un gobierno que de antemano estaba sentenciado. ${ }^{33}$

$\mathrm{Al}$ cambio de régimen, un numeroso grupo de "maestros oprimidos, cansado de las vejaciones de que ha sido objeto desde hace ya varios años", dirigió una carta abierta al secretario interino. En ella se exponía el viejo sistema de prebendas que había significado el manejo de la Dirección General. La misiva daba cuenta de "un grupo exclusivo de profesores" que se había adueñado de los más importantes puestos y disponía de "las comisiones, dispensas, prerrogativas y disimulos". Se decía que había profesores que gozaban de "magníficas habitaciones pagadas por el gobierno, casas cuyo arrendamiento pudiera ser de más de cien pesos mensuales", mientras que muchos otros más de igual categoría "disponen de un cuchitril para su familia". ${ }^{34}$

Vera Estañol, sin embargo, no compartía las dificultades de los docentes. Calificados por él mismo como "proletarios profesionistas", el secretario interino de Instrucción Pública y Bellas Artes veía a los maestros de primaria como "intelectualidades medianamente cultas, malogradas por exceso de la oferta y deficiencia de la demanda; espíritus despechados; ambiciones no satisfechas; aspiraciones irrealizadas; fermentos todos de la desintegración social" (Morales, 1987, pp. 22-23).

La propia Secretaría, convertida en una pieza de discordia y una de las posiciones negociadas por Madero en el gobierno interino de León de la Barra, se vislumbraba como el bastión de una nueva política. En agosto de 1911 el doctor Vázquez Gómez quedó al frente del despacho sustituyendo a Vera Estañol, pues se pensó que con él se podían cimentar las bases para lograr un cambio radical en la regulación educativa, es decir, alcanzar la federalización y al mismo tiempo la transición pacífica para el nuevo presidente. ${ }^{35}$

${ }^{33}$ El apartidismo es una calificación del propio Vera Estañol, quien relata que el primer ofrecimiento de Díaz fue el del Ministerio de Gobernación, mismo que no aceptó, y como segunda opción le dio el de Instrucción Pública.

${ }^{34}$ Podredumbre en la Secretaría de Instrucción pública. El Diario del Hogar, 19 de agosto de 1911, p. 1.

35 Madero designó a seis ministros, que formaron el primer gabinete de De la Barra. Los hermanos Vázquez Gómez, Emilio y Francisco, fueron ubicados en la Secretaría de Gobernación y en la de Instrucción Pública respectivamente. Este último había formado parte del Consejo Superior de Educación que fue el cuerpo consultivo más importante durante el mandato de Sierra.

\section{()(1) $\$$}


La Dirección General de Educación Primaria fue encomendada a Miguel Rodríguez y Cos, quien a lo largo de su carrera había sido maestro de escuelas tanto municipales y particulares como nacionales. Fundó una escuela privada llamada Católica Polimática, y fue jefe de sección en la Dirección General durante el porfiriato, lo que le permitió ser uno de los consentidos por el antiguo régimen al ser enviado con una beca a Estados Unidos para estudiar los sistemas educativos ("Nuevo director", 1911).

En medio de los cambios políticos, la Dirección General llevó a cabo reiterados intentos por contener a sus empleados, y en los oficios se advertía que "los maestros pueden concurrir a las casillas electorales, ejercitar todos sus derechos políticos pero de eso a convertirse en politicastros hay una distancia inconmensurable y esto último es lo que condenamos" "Cuál deberá", 1912). Los exhortos a directores de las escuelas confirmaban la politización de los maestros pues los conminaban a que "[...] se abstengan de formar dentro del plantel agrupaciones de carácter político a favor de cualquier partido, por ser ello perjudicial a la disciplina". ${ }^{36}$ Se les reiteraba que, con el objeto de no destruir el orden interno que debía existir en la jerarquía del personal docente, era "indispensable repartir responsabilidades en tal forma, que todos obedezcan a quien deban obedecer y todos manden a quien deban mandar [sic]" ${ }^{37}$ Era evidente que la estructura burocrática de la Dirección se había fracturado.

Desde la prensa se proponía a la opinión pública que los profesores se resistían al cumplimiento de sus deberes, pues "están a la misma altura que nuestros obreros que se declaran en huelga cuando los patrones les niegan la reducción inmoderada de las horas de trabajo". En la misma nota de El Diario del Hogar se decía que "una huelga de maestros sería cosa de ver por lo transcendental y chusca". ${ }^{38}$ La escisión interna del magisterio fue expuesta por los diarios, pues los normalistas alegaban que los maestros especiales eran unos improvisados y estaban mejor pagados que ellos. Las noticias daban cuenta de encarnizadas críticas sobre sueldos, corrupción imperante, remuneraciones poco equitativas y prebendas en los puestos más importantes. ${ }^{39}$

El clamor, decía la prensa, "tanto en las humildes escuelas de los barrios como en las hermosas del centro de la capital”, era que Vázquez Gómez debía renunciar por déspota y autoritario. En cuanto a Rodríguez y Cos, se

${ }^{36}$ Escuela elemental 47, 126 y 89. Vol. 2544, s/exp. AHgDF, México.

37 Escuela elemental 47, 126 y 89. Vol. 2544, s/exp. AHGDF, México.

${ }^{38}$ El horario corrido en las escuelas. El Diario del Hogar, 11 de septiembre de 1911, p. 3.

39 El nepotismo del Dr. Vázquez Gómez. El Diario del Hogar, 15 de octubre de 1911, p. 5.

\section{()(1) $(9$}


le acusó de torpe, pues trataba a los maestros como lacayos. ${ }^{40}$ Finalmente, a finales de 1911 se vio con beneplácito el anuncio de que ambos dejaban la Secretaría y la Dirección General respectivamente. El primero para dedicarse a su campaña por el partido antirreeleccionista y el segundo a la vida privada. Bajo el titular de "Sensacionales reformas en instrucción pública", la prensa vislumbró que con las remociones habría una mejor retribución para los profesores, el fin del monopolio de un grupo y la creación de un nuevo reglamento interior para las escuelas donde los maestros podían intervenir. ${ }^{41}$

Con la promesa de democratizar sus derechos, los profesores cerraron filas con Madero en las elecciones de 1912 y se comprometieron a reorganizar la escuela primaria, "base forzosa de toda organización social" (Morales, 1987, p. 58). Con ello, el magisterio pretendía abrir con sus expectativas una limitación institucional que había estado cerrada hasta entonces. Sin embargo, ¿cómo podría reconstruirse una estructura anquilosada como la Dirección General, que estaba basada en un mando burocrático centralizado, que impedía la participación y acaparaba beneficios para unos cuantos? Como cualquier grupo de presión, los maestros eran los primeros interesados en promover la expansión de sus actividades. Sin embargo, la posibilidad de abrir canales de comunicación se derrumbó ante la falta de una autoridad competente. Las reglas fueron puestas en tela de juicio pero no hubo sustitución por otras. Los oficios internos confirman el tamaño de las concesiones de tipo clientelar otorgadas a algunos maestros, pues muchos de ellos podían ahora definir su propio horario laboral y también podían decidir sobre los libros de texto que querían utilizar. ${ }^{42}$

La Dirección hizo llamados recurrentes a los docentes a respetar la disciplina y la armonía que debía de reinar entre ellos. Muchas veces, los profesores pasaban de una escuela a otra dejando a los alumnos sin atender, pedían licencia por enfermedad y no volvían a presentarse al trabajo. ${ }^{43}$ La misma Secretaría, rehén de la lucha política, se debatió entre una postura conservadora de su primer titular Miguel Díaz Lombardo, quien duró tres meses en el cargo, y los tibios intentos paliativos de José María Pino Suárez, quien ejerció al mismo tiempo el cargo de vicepresidente. En medio de la confusión

40 ¿Cuáles son los méritos del señor Rodríguez y Cos? El Diario del Hogar, 1 de noviembre de 1911, p. 1.

${ }^{41}$ Sensacionales reformas en instrucción pública. El Diario del Hogar, 28 de diciembre de 1911, p. 1.

${ }^{42}$ Instrucción pública en general. Vol. 2559, s/exp. 1912. AHGDF, México.

${ }^{43}$ Escuela elemental 47, 126 y 89. Vol. 2544. AHgDF, México.

\section{()(1) $(9$}


nacional y la precipitación a la baja de los salarios, el 28 de enero de 1912 el secretario informó que la Dirección había tenido un papel pasivo "esperando que la superioridad interpretara la ley [de 1908]" ("Informe leído", 1912). Los derechos de jubilación y prestaciones de los maestros quedaron en vilo.

Finalmente, el régimen huertista suprimió el 22 de noviembre de 1913 la Dirección General de Instrucción Primaria y la sustituyó por una jefatura. Su desaparición causó sensación e incertidumbre entre el magisterio. Se anunció como una muy buena decisión, pues la oficina había sido "una rémora para el progreso de la educación primaria y un semillero de malas voluntades y disgusto para los pedagogos que de ella han dependido". ${ }^{44}$ Con ello se vislumbraba una nueva era en la que quedarían erradicados los vicios burocráticos para los profesores, como los largos y fastidiosos trámites y la dignificación del gremio. ${ }^{45}$

Una especie de "borrón y cuenta nueva", pues la jefatura tendría la obligación, entre otras cosas, de formar y revisar nuevamente los expedientes con la hoja de servicios de los empleados, registrar los títulos de los maestros y defender sus derechos. Con ello, también se aseguraba la lealtad al régimen de Huerta, pues con este nuevo despacho se abría una posibilidad para que los profesores pudieran realizar una carrera dentro del orden jerárquico y se dejaran de considerar los cargos públicos como privilegios para los mismos funcionarios de siempre. También era una oportunidad para una nueva cacería de brujas y el momento para lograr una limpieza contra los detractores.

\section{CONSIDERACIONES FINALES}

Si bien la Dirección General de Educación Primaria desplegó una nueva racionalidad burocrática que permitió contratar más profesores, homologar el sueldo de los maestros y las maestras, asegurar la certeza en la remuneración de los empleados y fijar un escalafón, el resquebrajamiento institucional hacia finales de 1912 dejó en claro las grandes contradicciones de la política magisterial del régimen porfiriano.

${ }^{44}$ La supresión de la Dirección General de Educación ha sido bien acogida. El Independiente, 22 de noviembre de 1911, p. 1.

${ }^{45}$ La supresión de la Dirección General de Educación ha sido bien acogida. El Independiente, 22 de noviembre de 1911, p. 1.

\section{()(1) $\$$}


En efecto, lograr la uniformidad educativa en el país era impensable sin la actuación regulada de los docentes, quienes serían considerados empleados federales y concebidos como agentes de la modernización pedagógica. Sin embargo, al enfatizar las facultades de vigilancia y supervisión en la estructura burocrática sobre aquellas que le hubieran permitido al magisterio tener un mayor margen de participación, cierta autonomía en las decisiones y contar con su experiencia, la Dirección General de Educación Primaria redujo a los maestros a ser meros alumnos, y los concibió como simples instrumentos de la política educativa.

Los profesores fueron ubicados en el papel de subordinados sin posibilidad de escalar en la jerarquía burocrática, ya que los puestos, casi a la manera corporativa, pertenecían a quienes los detentaban. Resultado de ello, el magisterio se conformó como un grupo básicamente femenino, pero también heterogéneo y fragmentado en su interior. A la manera de un aparato ortopédico, la Dirección General sujetó, sancionó e inmovilizó a los docentes en función de beneficios discrecionales y selectivos. Las sociedades magisteriales autónomas en el Distrito Federal fueron bloqueadas o puestas al servicio de la estructura burocrática hasta el fin del régimen porfiriano, lo que evidencia que las autoridades educativas veían en la organización independiente de los profesores un peligro.

A pesar de ello, la crisis política en 1911 abrió una oportunidad de participación para los maestros. Su respuesta, como actores políticos en las elecciones presidenciales, evidenció un cúmulo de intereses que bien podían leerse como una amenaza o bien como una oportunidad para generar nuevas redes clientelares. Así lo entendió el régimen maderista, quien concedió favores a diestra y siniestra sin modificar, no obstante, la estructura de la Dirección, que mantenía atados los intereses de unos cuantos que detentaban el poder.

El resultado fue un vacío de autoridad y la falta de unidad del magisterio que pronto fue corregida. Después del golpe de Estado, la jefatura que sustituyó la obsoleta estructura del régimen porfiriano se encargó de "purgar" los elementos hostiles al régimen huertista, al mismo tiempo se intentó socializar una cultura militar acorde con los principios de defensa nacional. Se ordenó a los maestros que concurrieran a clases portando uniforme, pues finalmente se buscaba que la ropa simbolizara una identificación con los principios y las líneas de mando. Se les instó, bajo amenaza de cese, a que se abstuvieran de tratar con sus alumnos o subalternos cuestiones políticas. ${ }^{46}$

${ }^{46}$ Escuela elemental 47, 126 y 89. Vol. 2544. AHGDF, México.

\section{(ㄷ)(1) $(3$}


Con la cultura de guerra se pretendió establecer una identidad colectiva, un tipo de cohesión sobre los principios de moralidad y buen desempeño, que disfrazaron la nueva prótesis magisterial.

\section{LISTA DE REFERENCIAS}

Adiciones y reformas al reglamento aprobadas en la sesión del día 10 de febrero de 1906. (20 de febrero de 1906). La Enseñanza Primaria, II(5).

Acuerdo para realizar las sesiones de la Academia de profesores. (30 de julio de 1904). La Enseñanza Primaria, I(16).

Arnaut, A. (1996). Historia de una profesión: los maestros de educación primaria en México, 1887-1994. México: CIDE.

Bases constitutivas de la Academia de profesores. (30 de agosto de 1904). La Enseñanza Primaria, I(18).

Blau, P. (1968). The Hierarchy of Authority in Organizations. American Journal of Sociology, 73(4), 453-467.

Bonilla, J. M. (15 de enero de 1908). Papel de un director de escuela. La Enseñanza Primaria, VII(14).

Cano, G. (2000). Género y construcción cultural de las profesiones en el porfiriato: magisterio, medicina, jurisprudencia y odontología. Historia y Grafía, 14, 206-243.

Chaoul, M. E. (2002). El Ayuntamiento de la ciudad de México y los maestros municipales, 1867-1896. Secuencia, 53, 79-101.

Circulares. (20 de febrero de 1904a). La Escuela Mexicana, I(1).

Circulares. (10 de abril de 1904b). La Escuela Mexicana, I(5).

Circulares. (20 de julio de 1904c). La Escuela Mexicana, I(15).

Circulares. (20 de mayo de 1905). La Escuela Mexicana, II(14).

Circulares. (20 de febrero de 1906). La Escuela Mexicana, III(5).

Circulares. (10 de julio de 1911). La Escuela Mexicana, VIII(6).

Circular relativa al auxilio que se ministra a las familias de empleados públicos que fallezcan en el desempeño de sus funciones. 19 de septiembre de 1905. (Abril de 1906). Boletín de Instrucción Pública, v(8).

Cortada, E. (2000). El Acceso de las maestras al magisterio público en el siglo xIx: ¿concesión o logro profesional? Historia Social, 38, 35-56.

¿Cuál deberá ser la actitud de los maestros de escuela? (20 de enero de 1912). La Escuela Mexicana, VIII(18).

Deberes oficiales y deberes morales. (15 de julio de 1909). La Enseñanza Primaria, IX(2).

\section{()(1) $\$$}


Deberes oficiales y deberes morales. (15 de junio de 1911). La Enseñanza Primaria, $x(24)$.

Dictamen de la Comisión del Consejo Superior de Educación Pública encargada de estudiar el proyecto de ley de educación primaria a dicho Consejo por la Secretaría de Instrucción Pública y Bellas Artes. 19 de diciembre de 1907. (Junio de 1908). Boletín de Instrucción Pública, vi.

Discurso pronunciado por el C. Lic. Ezequiel A. Chávez en la distribución de premios efectuada el $1^{\circ}$ de marzo de 1906. (Junio de 1906). Boletín de Instrucción Pública, $V$.

Dublán, A. y Esteva, A. (1898). Colección legislativa completa de la República Mexicana, con todas las disposiciones expedidas para la federación, el Distrito Federal y los territorios federales (t. xxvi). México: Tipografía de "El Partido Liberal".

Fowler, W. (1996). The Compañía Lancasteriana and the Elite in Independent Mexico, 1822-1845. Tesserae, Journal of Iberian and Latin American Studies, 16(2), 81-110.

Galván, L. E. (1991). Soledad compartida. Una historia de maestros, 1908-1910. México: CIESAS.

Informe anual leído por el Secretario de la Dirección General en la distribución de premios que el día 3 de mayo de 1904 se hizo en el Teatro Arbeu a los alumnos distinguidos de las escuelas primarias de la capital. (10 de mayo de 1904). La Enseñanza Primaria, I(8).

Informe de los trabajos de la Asociación Nacional del Magisterio presentados por el primer secretario de la Junta Central Directiva en el acto inaugural el día 27 de enero de 1911. (20 de marzo de 1911). La Escuela Mexicana, VII(36).

Informe leído por el secretario el 28 de enero de 1912 con la asistencia del presidente. (10 de abril de 1912). La Escuela Mexicana, viri(23).

Iniciativa para la organización de la Asociación Nacional del Magisterio. (1 de febrero de 1909). La Enseñanza Primaria, viII(18).

La Academia de Profesores del Distrito Federal. (30 de septiembre de 1904). La Enseñanza Primaria, I(22).

La Asociación Nacional del Magisterio. (15 de marzo de 1909). La Enseñanza Primaria, $\operatorname{VIII}(18)$.

Lamberti, M. (1989). State, society and the elementary school in imperial Germany. Londres: Oxford University Press.

Liceaga, E. (1949). Mis recuerdos de otros tiempos. México: Talleres Gráficos de la Nación.

Los profesores deben saludar a la bandera. (15 de julio de 1909). La Enseñanza Primaria, $\operatorname{Ix}(2)$.

Meneses, E. (1983). Tendencias educativas oficiales en México, 1821-1911. México: Editorial Porrúa.

\section{()(1) $(3$}


Morales, A. (1987). Maestros de la revolución mexicana. Centenario de la Escuela Nacional de Maestros. México: INEHRM.

Nuevo director de Educación Primaria. (20 de julio de 1911). La Escuela Mexicana, VII (7).

Presupuesto de la Secretaría de Instrucción Pública y Bellas Artes. Año fiscal 19081909. (Noviembre de 1908). Boletín de Instrucción Pública, XI.

Proyecto de ley de educación primaria presentado por la Secretaría de Instrucción Pública y Bellas Artes, para su estudio, al Consejo Superior de Educación Pública. (Julio-agosto de 1908). Boletín de Instrucción Pública, x.

Proyecto de reglamento para la inspección de escuelas. (15 de julio de 1911). La Enseñanza Primaria, $\mathrm{x}(25)$.

Reglamento para la escuela Normal de Profesores de instrucción primaria en la ciudad de México. (1887). México: Imprenta del Gobierno, en el Ex-Arzobispado.

Una iniciativa acerca de la nueva ley. (15 de julio de 1909). La enseñanza primaria, $\operatorname{IX}(2)$.

Vera, J. (1957). La Revolución Mexicana, orígenes y resultados. México: Editorial Porrúa, S. A.

Weber, M. (1977). ¿Qué es la burocracia? Buenos Aires: Editorial La Pléyade.

\section{OTRAS FUENTES}

\section{Archivo}

AHGDF Archivo Histórico del Gobierno del Distrito Federal.

\section{Hemerografía}

El Popular.

El Diario del Hogar.

El Independiente.

El Educador Moderno. 